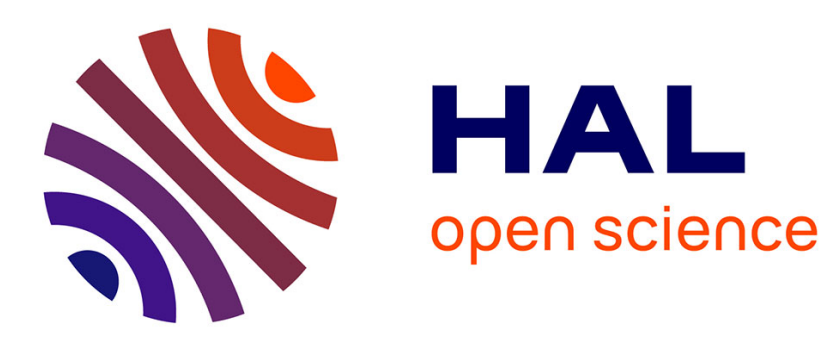

\title{
Evidence for Gallagher-Moszkowski doublets in 180Ta
}

\author{
E. Warde, R. Seltz, G. Costa, D. Magnac, C. Gerardin
}

\section{To cite this version:}

E. Warde, R. Seltz, G. Costa, D. Magnac, C. Gerardin. Evidence for GallagherMoszkowski doublets in 180Ta. Journal de Physique Lettres, 1978, 39 (11), pp.161-164. 10.1051/jphyslet:019780039011016100 . jpa-00231468

\section{HAL Id: jpa-00231468 https://hal.science/jpa-00231468}

Submitted on 1 Jan 1978

HAL is a multi-disciplinary open access archive for the deposit and dissemination of scientific research documents, whether they are published or not. The documents may come from teaching and research institutions in France or abroad, or from public or private research centers.
L'archive ouverte pluridisciplinaire HAL, est destinée au dépôt et à la diffusion de documents scientifiques de niveau recherche, publiés ou non, émanant des établissements d'enseignement et de recherche français ou étrangers, des laboratoires publics ou privés. 


\title{
EVIDENCE FOR GALLAGHER-MOSZKOWSKI DOUBLETS IN ${ }^{180} \mathrm{Ta}$
}

\author{
E. WARDE $(*)$, R. SELTZ, G. COSTA, D. MAGNAC and C. GÉRARDIN \\ C.R.N. and U.L.P., Basses Energies, 67037 Strasbourg, France
}

(Reçu le 3 avril 1978, accepté le 12 avril 1978)

\begin{abstract}
Résumé. - A partir d'une étude expérimentale du ${ }^{180} \mathrm{Ta}$ par la réaction $(\mathrm{p}, \mathrm{d})$, on déduit les éléments de matrice de l'interaction résiduelle neutron-proton pour certains doublets GallagherMoszkowski.
\end{abstract}

\begin{abstract}
Some residual neutron-proton interaction matrix elements have been deduced for band-head doublets in the odd-odd nucleus ${ }^{180} \mathrm{Ta}$ from a spectroscopic study using the $(\mathrm{p}, \mathrm{d})$ reaction.
\end{abstract}

Spectroscopic studies of odd-odd nuclei in the rare earth region have been widely used in the frame of a given model to deduce an estimate of the effective residual interaction $V_{\mathrm{np}}$ between the unpaired proton and the neutron.

Following Boisson et al. [1] the Hamiltonian of an odd-odd axially symmetric nucleus is given by

$$
\mathscr{H}=H_{\mathrm{adiab}}+H_{\mathrm{RPC}}+V_{\mathrm{np}}
$$

where $H_{\text {adiab }}$ is the adiabatical part of the Hamiltonian and $H_{\mathrm{RPC}}$ corresponds to the Coriolis coupling.

The intrinsic part of the eigenfunction of $H_{\text {adiab }}$ is a direct product of the Nilsson states of the unpaired proton and the neutron $\chi_{\mathrm{k}}=\chi_{\Omega_{\mathrm{p}}} \chi_{\Omega_{\mathrm{n}}}$. Because of axial symmetry the projections of the spins $\Omega_{\mathrm{p}}$ and $\Omega_{\mathrm{n}}$ can couple either parallel or antiparallel giving the projection quantum numbers for the resulting band-head doublet

$$
K_{>}=\left|\Omega_{\mathrm{p}}\right|+\left|\Omega_{\mathrm{n}}\right| \text { and } K_{<}=\left|\Omega_{\mathrm{p}}-\Omega_{\mathrm{n}}\right|
$$

with $\Omega=\Lambda+\Sigma$ and $\Sigma= \pm \frac{1}{2}$, corresponding to spin up $\uparrow$ or down $\downarrow$ respectively.

Following the Gallagher-Moszkowski (G-M) empirical rule, the lower-energy member of the doublet corresponds to parallel coupling of the intrinsic spins [2]. It may be the $K_{>}$or the $K_{<}$state. The parity $\Pi$ is deduced from the parities of the odd-particle states : $\Pi=\Pi_{\mathrm{p}} \cdot \Pi_{\mathrm{n}}$.

In the absence of Coriolis coupling and neglecting

$\left(^{*}\right)$ On leave from University of Lattakia (Syria). the off-diagonal elements of $V_{\mathrm{np}}$, the energy separation of the doublet band-head members is given by

$$
\begin{aligned}
E_{K<}- & E_{K>}=\frac{h^{2}}{2 f}\left(K_{<}-K_{>}\right)+A+(-1)^{I} \times \\
& \times B \delta_{K, 0}+(-1)^{I} \frac{h^{2}}{2 f} a_{\mathrm{p}} a_{\mathrm{n}} \delta_{K, 0} \delta_{\left|\Omega_{\mathrm{p}}\right|, 1 / 2}
\end{aligned}
$$

where $A$ is the G-M term, $B$ the Newby term of $V_{\mathrm{np}}$ which appears only for $K=0$ [3], and $a$ the decoupling parameter.

The aim of this paper is to estimate the two terms $A$ and $B$ from an experimental study of ${ }_{73}^{180} \mathrm{Ta}_{107}$. Spectroscopic information on this nucleus was very poor up to now. Only two states, both isomeric, were known : the ground state with spin $8^{+}$or $9^{-}$,

$$
T_{1 / 2}>10^{3} \mathrm{y},
$$

and a $1^{+}$state, $T_{1 / 2} \approx 8 \mathrm{~h}$, at $32 \mathrm{keV}[4,5]$. An experimental study of the ${ }^{181} \mathrm{Ta}(\mathrm{p}, \mathrm{d}){ }^{180} \mathrm{Ta}$ reaction was therefore undertaken.

With the assumption of a direct reaction mechanism, the odd proton is a spectator such that its orbit is the same as in the ground state of the target ${ }^{181} \mathrm{Ta}$ i.e. $7 / 2^{+}[404 \downarrow]$. States observed in the low-energy part of the resulting ${ }^{180} \mathrm{Ta}$ spectrum are therefore members of the rotational bands built on intrinsic states obtained by the coupling of the $7 / 2^{+}[404 \downarrow]$ proton configuration with the neutron intrinsic states of the neighbouring isotones $\left({ }^{179} \mathrm{Hf},{ }^{181} \mathrm{~W} \ldots\right)$.

The reaction has been studied at $E_{\mathrm{p}}=19 \mathrm{MeV}$ on the Strasbourg MP tandem. The outgoing deuterons were detected in the focal plane of a Buechner magnet spectrograph and recorded in four position sensitive 

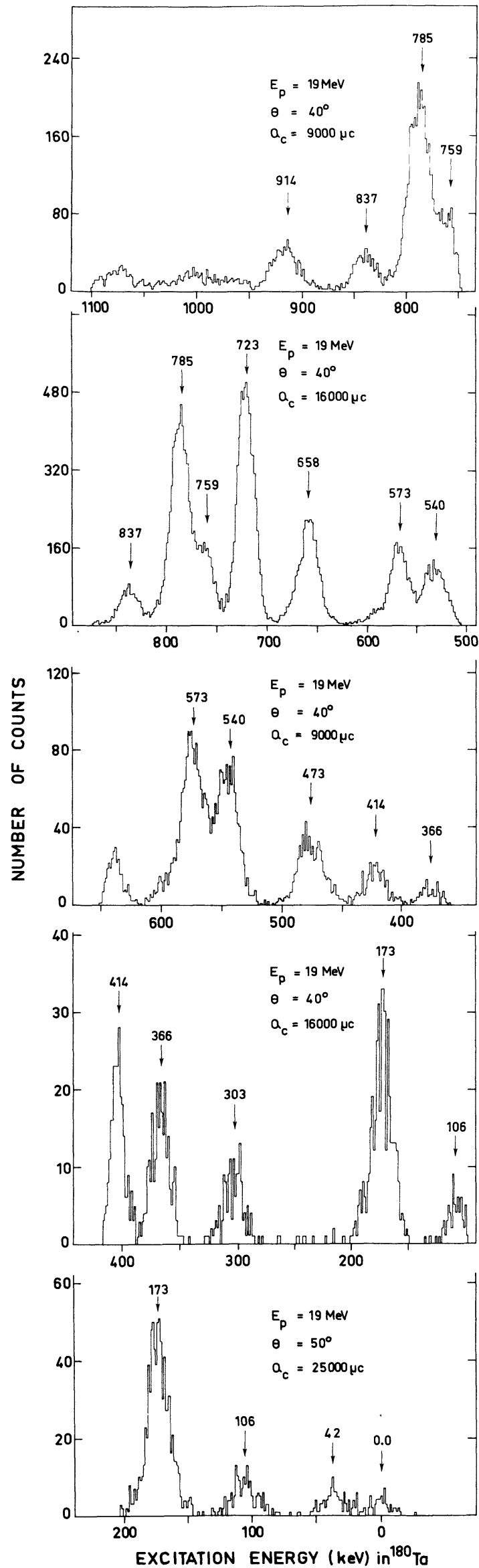

FIG. 1. - Experimental spectra for the ${ }^{181} \mathrm{Ta}(\mathrm{p}, \mathrm{d}){ }^{180} \mathrm{Ta}$ reaction observed in various detectors with overlapping magnetic fields. detectors. Targets of $\approx 200 \mu \mathrm{g} / \mathrm{cm}^{2}$ of natural tantalum have been used giving an overall resolution of about $15 \mathrm{keV}$. Figure 1 shows experimental spectra observed in various detectors with overlapping magnetic fields. The absolute error for excitation energies was estimated to be better than $5 \mathrm{keV}$. Various $(\mathrm{p}, \mathrm{d})$ reactions on light nuclei have been used for the spectrograph calibration. The excitation energies reported in figure 1 refer to the centre of gravity of the peaks obtained through a curve fitting program.

Twenty-one levels are observed up to $1 \mathrm{MeV}$ excitation and most of their angular distributions were measured. A preliminary report of this experiment was given in a recent communication [6].

In the DWBA analysis, the optical model parameters were taken from the survey of Elbek and Tjom [7]. For comparison with experiment only transfers with $(\mathrm{d} \sigma / \mathrm{d} \Omega)_{\max } \geqslant 1 \mu \mathrm{b} / \mathrm{sr}$ have been considered. Some angular distributions show obvious $l$ values. This was a great help in the first step of the identification of the states. The identification of observed levels with levels predicted by the model was obtained through the following procedure.

1) The band-head energies were estimated with the aid of equation (43) in reference [8] from known Nilsson neutron states in ${ }^{179} \mathrm{Hf}$ [9] e.g. $9 / 2^{+}[624 \uparrow]$, $7 / 2^{-}[514 \downarrow], 1 / 2^{-}[510 \uparrow], 5 / 2^{-}[512 \uparrow], 1 / 2^{-}[521 \downarrow]$ and $3 / 2^{-}[512 \downarrow]$; the initial values of matrix elements of $V_{n p}$ and inertia parameters are taken from reference [1] and estimated from neighbouring nuclei [10], respectively.

2) The initial values of these parameters are varied in order to obtain the best agreement between theory and experiment in reproducing (i) the energy spectrum, (ii) the angular distribution shapes and (iii) the absolute cross section [11].

The final values for the $A$ and $B$ terms of equation (2) are then deduced. Among the odd-parity levels, the two states $I^{\pi}=3^{-}$and $I^{\pi}=4^{-}$due to the coupling p $7 / 2^{+}[404 \downarrow]$, n $1 / 2^{-}[521 \downarrow]$ are expected to have the largest cross sections in the excitation energy range considered. They are identified as the main components of the two peaks observed in the spectrum at 785 and $723 \mathrm{keV}$, where angular distributions show dominant $l=1$ transfer as expected (Fig. 2). Solid

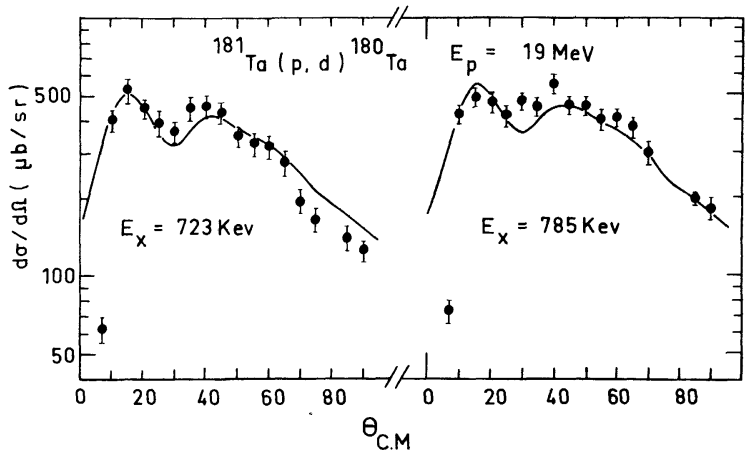

Fig. 2. - Angular distribution of levels at $723 \mathrm{keV}$ and $785 \mathrm{keV}$. Solid lines are DWBA calculations (see text) 
TABLE I

Comparison of the theoretical energies and cross-sections with the experimental values. Energies are in $\mathrm{keV}$

\begin{tabular}{|c|c|c|c|c|c|c|c|c|c|c|c|c|c|c|c|}
\hline \multirow{2}{*}{$E_{\text {exp }}$} & \multirow{2}{*}{$\begin{array}{c}E_{\mathrm{th}} \\
\text { (perturbed) }\end{array}$} & \multirow{2}{*}{$I^{\pi}, K^{\pi}$} & \multicolumn{10}{|c|}{ Eigenstates } & \multirow{2}{*}{\multicolumn{2}{|c|}{$\begin{array}{l}\sigma_{\mathrm{th}}\left(45^{\circ}\right) \\
(\mu \mathrm{b} / \mathrm{sr})\end{array}$}} & \multirow{2}{*}{$\begin{array}{c}\sigma_{\text {exp }}\left(45^{\circ}\right) \\
(\mu \mathrm{b} / \mathrm{sr})\end{array}$} \\
\hline & & & $0^{-}$ & $1^{-}$ & $2^{-}$ & $3_{1}^{-}$ & $3-$ & $4_{1}^{-}$ & $4_{2}^{-}$ & $5^{-}$ & $6^{-}$ & $7^{-}$ & & & \\
\hline \multirow{3}{*}{173} & 189 & $4^{+}, 1^{+}$ & & & & & & & & & & & 6.3 & \multirow{3}{*}{39.3} & \multirow{3}{*}{$34 \pm 5$} \\
\hline & 180 & $8^{+}, 8^{+}$ & & & & & & & & & & & 10.5 & & \\
\hline & 170 & $7^{-}, 7^{-}$ & & & & & & & & & 0.088 & 0.996 & 22.5 & & \\
\hline 723 & 727 & $4^{-}, 4_{2}^{-}$ & & & 0.012 & -0.392 & -0.136 & 0.320 & 0.910 & & & & & 306 & $430 \pm 35$ \\
\hline \multirow{3}{*}{785} & 776 & $6^{-}, 1^{-}$ & 0.646 & 0.762 & & & & & & & & & 3.9 ) & \multirow{3}{*}{356.4} & \multirow{3}{*}{$460 \pm 40$} \\
\hline & 788 & $3^{-}, 3_{2}^{-}$ & & & 0.181 & 0.017 & 0.983 & & & & & & 330.7 & & \\
\hline & 802 & $6^{-}, 3_{1}^{-}$ & & & 0.097 & -0.778 & 0.040 & -0.240 & -0.538 & -0.185 & -0.001 & & 21.8 & & \\
\hline
\end{tabular}

curves are theoretical predictions for levels with eigenstate components reported in table I. A normalization factor $\frac{\sigma(\theta)_{\text {exp }}}{\sigma(\theta)_{\text {th }}}=1.3$ was necessary in order to obtain the fits of figure 2. Due to the experimental resolution, it is likely that observed peaks are multiplets including members of other bands contributing to the measured cross section. In the case of the two states studied here such a contribution has been estimated to be smaller than $10 \%$. In table II, the G-M term deduced from this experiment is compared to values from other nuclei.

The G-M doublet based on the p 7/2+ [404 $\downarrow$, n $7 / 2^{-}[514 \downarrow]$ coupling is composed of $\left(7^{-}, 7\right)$ and $\left(0^{-}, 0\right)$ levels. The first one is found with a good evidence at $173 \mathrm{keV}$. Among the possible $C_{j l}^{\Omega}, j=11 / 2$, $l=5, \Omega=7 / 2$ is the most important one and $l=5$ is dominant in the shape of the angular distribution. The total value of the observed absolute cross section is explained by the presence in this region of the $8^{+}$ member of the $1^{+}, 8^{+}$G-M doublet $\mathrm{p} 7 / 2^{+}[404 \downarrow]$, n $9 / 2^{+}[624 \uparrow]$ deduced from the values of $A$ [1] and

\section{TABLE II}

Comparison with previous results of $\left\langle V_{\mathrm{np}}\right\rangle$ values deduced from this study. Energies are in $\mathrm{keV}$

\begin{tabular}{ccccc} 
& $\mathrm{p} 7 / 2^{+}[404 \downarrow]$, & $\mathrm{p} 7 / 2^{+}[404 \downarrow]$, \\
& $\mathrm{n} 1 / 2^{-}[521 \downarrow]$ & $\mathrm{n} 7 / 2^{-}[514 \downarrow]$ \\
& \multicolumn{1}{c}{${ }^{180} \mathrm{Ta}\left({ }^{a}\right)$} & ${ }^{174} \mathrm{Lu}\left({ }^{b}\right)$ & ${ }^{180} \mathrm{Ta}\left({ }^{a}\right)$ & ${ }^{176} \mathrm{Lu}\left({ }^{b}\right)$ \\
$E_{k<}-E_{k>}\left({ }^{c}\right)$ & $785-723$ & $433-365$ & $370-173$ & $241-0$ \\
$A$ & +103 & +73 & +238 & +253 \\
$B$ & & & +50 & +69
\end{tabular}

$\left({ }^{a}\right)$ Present experiment.

(b) Ref. [1].

(c) Eigenvalues of $\mathscr{X}$ (Eq. (1)). the rotational term. Furthermore, the $\left(4^{+}, 1\right)$ member of the $\left(1^{+}, 1^{+}\right)$band is also present in the same energy range and the sum of the contributions of these three states gives a better fit of the details of the angular distribution (Fig. 3).

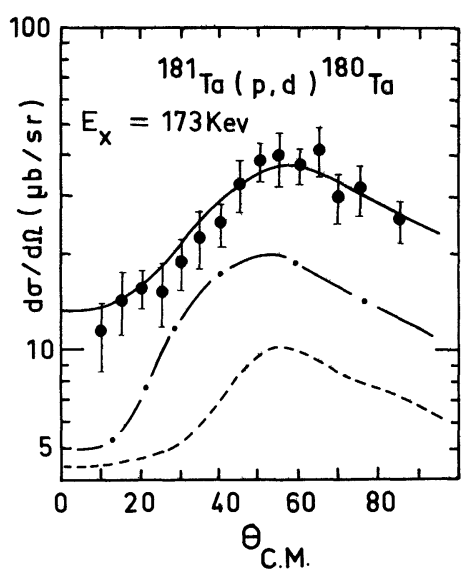

Fig. 3. - Angular distribution of a multiplet of states at $E_{x}=173 \mathrm{keV}$. The curves are DWBA fits. The dotted, the dasheddotted and the solid lines refer respectively to the $8^{+}, 8 ; 7^{-}, 7$ and the sum of three states $\left(8^{+}, 8 ; 7^{-}, 7\right.$ and $\left.4^{+}, 1\right)$.

The second member $\left(0^{-}, 0\right)$ of the doublet has a calculated cross section smaller than $1 \mu \mathrm{b} / \mathrm{sr}$ and therefore cannot be observed in the present experiment. According to the magnitude of the G-M term [1], one predicts this level to be located at $400 \pm 50 \mathrm{keV}$ because the Newby term here decreases the energy of the odd members of the $K=0$ rotational band. A relatively large experimental cross section is found for a level at $414 \mathrm{keV}$ which shows an $l=3$ angular distribution. The $l$-value and the cross section are accounted for by the expected states in this region; i.e. the $\left(1^{-}, 1\right)$ from the $p 7 / 2^{+}[404 \downarrow]$, n $5 / 2^{-}[512 \uparrow]$ 
coupling, the lowered $\left(2^{-}, 0\right)$ state and the $\left(3^{-}, 0\right)$ state. This places the unobserved $\left(0^{-}, 0\right)$ level at $370 \mathrm{keV}$. The resulting Newby term, $B=50 \mathrm{keV}$, and the shifts due to Coriolis coupling explain the positions of the observed members of this band.

The values of the matrix elements $V_{\mathrm{np}}$ deduced from this study are compared in table II with the values given by Boisson et al. [1] for other nuclei, where Coriolis coupling and off-diagonal effects of $V_{\mathrm{np}}$ were taken into account.

Acknowledgments. - We thank Dr. R. Piepenbring for stimulating discussions and a critical reading of the manuscript.

\section{References}

[1] Boisson, J. P., Piepenbring, R. and Ogle, W., Phys. Rep. 26 (1976) 99.

[2] Gallagher, C. J. and Moszkowski, S. A., Phys. Rev. 111 (1958) 1282.

[3] Newby, N. D., Phys. Rev. 125 (1962) 2063.

[4] Gallagher Jr., C. J., Jorgensen, M. and Skibreid, O., Nucl. Phys. 33 (1962) 285.

[5] Wapstra, A. H. and Gove, N. B., private communication quoted in Nucl. Data Sheets 15 (1975) 577.

[6] Warde, E., Costa, G. J., Gérardin, C., Magnac, D. and SeltZ, R., Proc. XV Winter School, Zakopane (1977) p. 277.
[7] ElbeK, B. and Tuom, P. O., Adv. Nucl. Phys. 3 (1969) 259.

[8] Jones, D. H., Ph. D. dissertation, Florida State University, Tallahassee (1969) unpublished.

[9] Bunker, M. E. and ReICH, C. W., Rev. Mod. Phys. 43 (1971) 348.

[10] Struble, G. L., Kern, J. and Sheline, R. K., Phys. Rev. 137 (1965) B 772.

[11] Elmore, D. E. and Alford, W. P., Can. J. Phys. 54 (1976) 1493. 